Gut, 1962, 3, 135

\title{
Pancreatic heterotopia as a cause of dyspepsia
}

\author{
R. D. TONKIN, T. E. FIELD, AND P. R. WYKES \\ From the Westminster Hospital, London, Queen Alexandra Military Hospital, \\ Milbank, London, and the Gordon Hospital, London
}

EDITORIAL SYNOPSIS Four cases of pancreatic heterotopia are reported. It is considered that this pathology may cause severe, persistent dyspepsia and may escape detection at laparotomy unless the stomach is opened.

Although pancreatic heterotopia was originally described as a pathological entity by Jean Schultz well over two centuries ago and its existence was confirmed histologically by Klob about 130 years later (Busard and Walters, 1950), it is today all too rarely considered as a possible cause of clinical symptoms. Having encountered several interesting examples of the condition, we considered that a brief review of the subject would serve a useful purpose at the present time. The most recent general review of the literature appears to be that of Pearson (1951).

Pancreatic heterotopia may be found in all age groups, although the condition is only rarely encountered in children. This is a little surprising in view of the fact that the condition is usually considered to be an antenatal anomaly. It manifests itself most frequently in the fourth and fifth decades, and seems to be somewhat more common in the male. Barbosa, Dockerty, and Waugh (1946) estimated that heterotopic deposits might be expected to be encountered once in every 500 upper abdominal explorations, and these authors also state that the incidence at routine necropsy has been variously reported as between $0.6 \%$ and $5.6 \%$.

In more than half the six hundred odd cases already described in the literature, the aberrant tissue was located in the wall of the stomach or duodenum and nearly always within $5 \mathrm{~cm}$. of the pylorus. Other sites include the jejunum, especially in a Meckel's diverticulum, the gall bladder or biliary tract, and the mesentery. It has even been reported outside the abdominal cavity. When the lesion is near the pylorus it is not surprising that symptoms occur and that there is frequent confusion with other more common pathologies. However, it is obviously important to attempt to establish the diagnosis of heterotopic pancreatic tissue when this is present, since surgical treatment need be far less radical than for the pathologies it may mimic.
There is no characteristic symptom complex for these juxtapyloric deposits, the chief complaint usually being that of epigastric or subcostal pain which may or may not bear a time relation to food, and which may or may not be responsive to antacid preparations (Denson, 1957; Krogh, 1957; Martinez, Morlock, Dockerty, Waugh, and Weber, 1958; Strelinger, 1957). Pyloric obstruction is not infrequently produced and several instances of severe gastrointestinal bleeding have been recorded (Bradley, Klein, and Levy, 1956; Hudock, Wanner, and Reilly, 1956; Vidgoff, 1957). Essentially there is a dyspepsia which even on critical analysis is often indistinguishable from that produced by a peptic lesion in one of its various forms.

The condition can occasionally be revealed by radiological examination, and in one series some abnormality was demonstrated in $74 \%$ of the cases (Martinez et al., 1958). The appearances were most frequently those of a polypoid tumour. The only truly diagnostic radiological feature is the demonstration of barium-filled excretory ducts within the boundaries of an antral filling defect of less than $1.5 \mathrm{~cm}$. in diameter (Littner and Kirsh, 1952; Rooney, 1959). Small lesions not demonstrable by repeated radiological examination may sometimes be seen at gastroscopy (Nelson and Scott, 1958). The appearances vary with the gastric layers predominantly involved, but the submucosal site is the commonest and in these cases the tumour presents a nipple-like appearance.

Microscopically the heterotopic tissue often extends deeper than is expected from naked-eye inspection, and muscle layers may be invaded. Acini and ducts are usually readily demonstrated, but islet cell tissue is less commonly present. Most of the pathological changes that affect the normal pancreas have been recorded as intrinsic changes of these heterotopic masses, including cysts, fatty atrophy, 
acute and chronic pancreatitis, also benign and malignant neoplastic changes of ductal, acinar, or islet cell tissue (Pearson, 1951). Possibly the most exceptional instance was reported by Ballinger (1941) in which an insular carcinoma had occurred in the aberrant pancreas and had metastasized widely.

The clinical course of pancreatic heterotopia involving the stomach or duodenum is usually benign, and in fact Eklöf (1961), in a report on 25 cases diagnosed radiologically at the Karolinska Institute between 1940 and 1960 , goes so far as to state that there was no evidence of symptoms being directly attributable to the aberrant deposits in any of these cases. However, there is no question that on occasion pain may be disturbingly persistent and not infrequently disproportionately severe. Most articles written on the subject imply that the severity of the symptoms is directly related to the size of the lesion, but that this is not necessarily so is suggested by the present cases. We felt that it would be informative to record these to emphasize that distressingly severe and persistent symptoms may be produced by very small lesions when located near the pylorus, so small indeed that they may all too easily be overlooked even at laparotomy unless the stomach is opened and the mucosa very carefully scrutinized.

In passing it is pertinent to mention that when heterotopic deposits are situated in the biliary passages, pathology of the gall tract may be simulated, and, when in the small intestine, the commonest form of clinical presentation is intussusception.

\section{CASE REPORTS}

CASE 1 A 50-year-old woman had a history of intermittent epigastric and right hypochondrial pain for 26 years. For many years the pain had awakened her in the early morning and was relieved by sodium bicarbonate. It bore an inconstant relation to meals, occasionally occurring immediately after eating.

There had been episodes of vomiting for two years, and one month previously the patient had been admitted to another hospital with epigastric pain, nausea, and vomiting. On examination stomach splashing was noted. Radiological examination showed no abnormality of the chest or gall bladder. A barium meal revealed a persistent fleck of barium at the base of the duodenal cap, with irregularity and lack of distensibility. Gastric emptying was delayed. A diagnosis of duodenal ulcer was made. The patient became free of symptoms with bed rest and a fluid diet but relapsed shortly after discharge.

On admission to the Queen Alexandra Military Hospital she was observed to be a fit but rather thin person. On abdominal examination a marked succussion splash and slight tenderness in the right hypochondrium were observed. The pelvic colon was loaded. Other systems showed no abnormality. The barium studies were

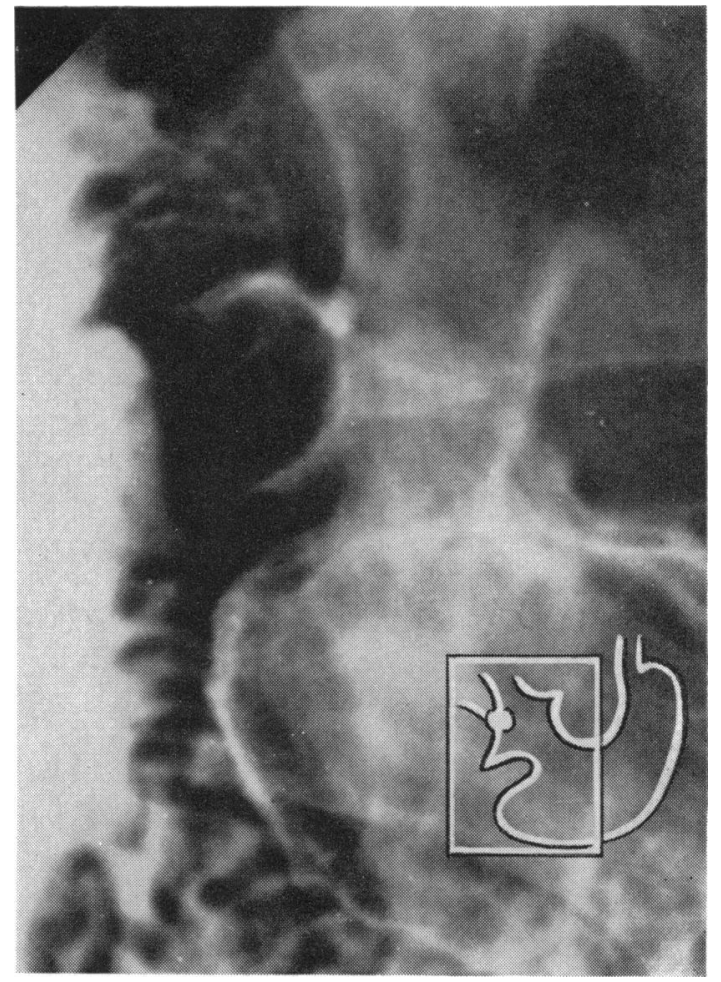

FIG. 1. Nipple-like appearance within the duodenal cap (Case 1).

repeated and the appearances were unchanged. Critical reinspection after the diagnosis had been established shows the nipple-like projection in the first part of the duodenum (Fig. 1).

At laparotomy a large fleshy subpyloric gland was noted and there were thick adhesions about the duodenum. Subtotal gastrectomy was performed, the duodenum being divided distal to the pathological area. Examination of the operation specimen showed no macroscopic abnormality, but on histological examination heterotopic pancreatic tissue was found in the submucosa together with considerable mucosal infiltration by plasma cells. The 'subpyloric gland' also consisted of heterotopic pancreatic tissue.

The patient has been free of symptoms since the operation.

CASE 2 This 40-year-old man had a five-year history of intermittent attacks of right hypochondrial pain radiating to the back, exacerbated by hunger or full meals but relieved by small feeds or antacid medication. The pain came on one hour after meals but never woke him at night and was never severe enough to interfere with his work. It was often associated with vomiting and he had had three episodes of haematemesis with melaena during the five years. The symptoms had become progressively more severe and persistent, but the patient's 
appetite was not impaired and he had not lost weight.

On examination the general condition was satisfactory. The abdomen was soft with slight midline epigastric tenderness. The liver and spleen were not palpable. Other systems were within normal limits.

A radiological examination after a barium meal showed a deformed duodenal cap with two questionable ulcer craters in the posterior wall and rather rapid gastric emptying. Haemoglobin was $103 \%$, E.S.R. $5 \mathrm{~mm} . / \mathrm{hr}$., and W.B.C. $9,800 /$ c.mm. with a normal differential count. Blood urea, serum proteins, and liver function tests were normal. Tests for occult blood in the stools were negative on three occasions.

A diagnosis of duodenal ulcer was made and subtotal gastrectomy performed. At operation the surgeon could not demonstrate an ulcer and careful examination of the operation specimen showed no macroscopic abnormality. Histology revealed large amounts of heterotopic pancreatic tissue in the submucosa and muscle layers of the stomach wall at the pyloric end of the specimen. The patient's only complaint since operation has been of occasional early morning anorexia.

CASE 3 A 41-year-old man presented with a persistent left subcostal pain of six months' duration. It bore no relation to food nor was it relieved by antacid medication. The pain was present throughout the night although not sufficiently severely to disturb sleep. The patient vomited bile on several occasions and complained bitterly of nausea and anorexia throughout. He had lost half a stone over the six months. More recently the pain had been associated with splashing and a sense of fullness in the epigastrium. Gastro-enterostomy had been performed 24 years before, presumptively for duodenal ulceration, after which he had been free from any significant symptoms.

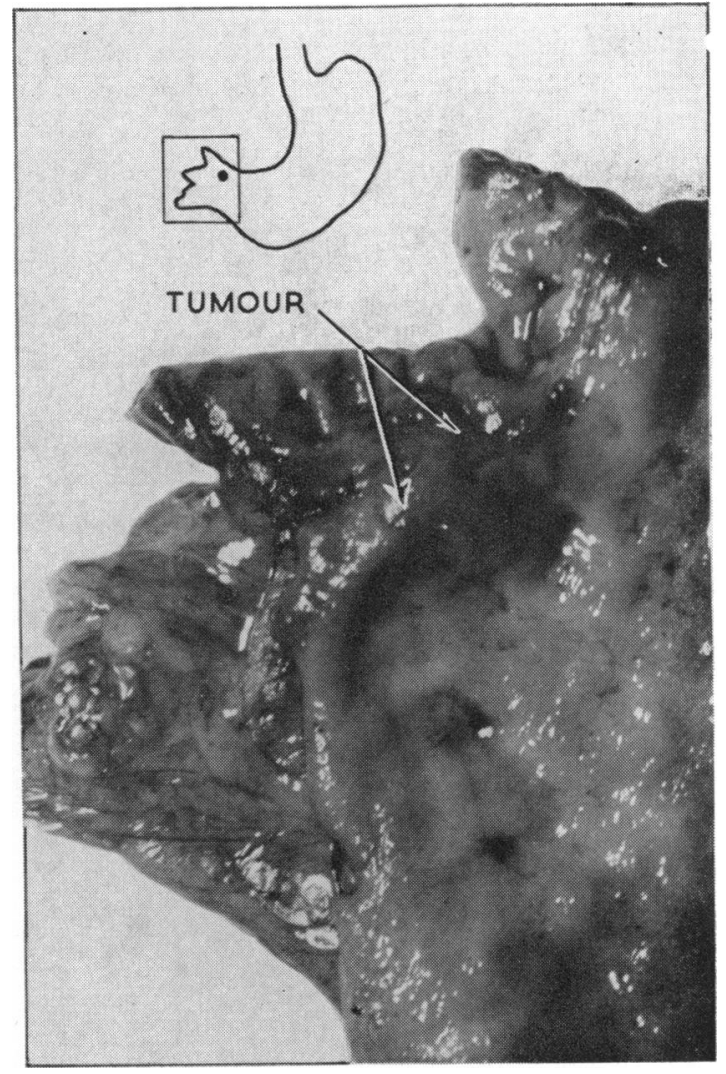

FIG. 2. Macroscopic appearances of the submucosal lesion adjacent to the pylorus (Case 3).

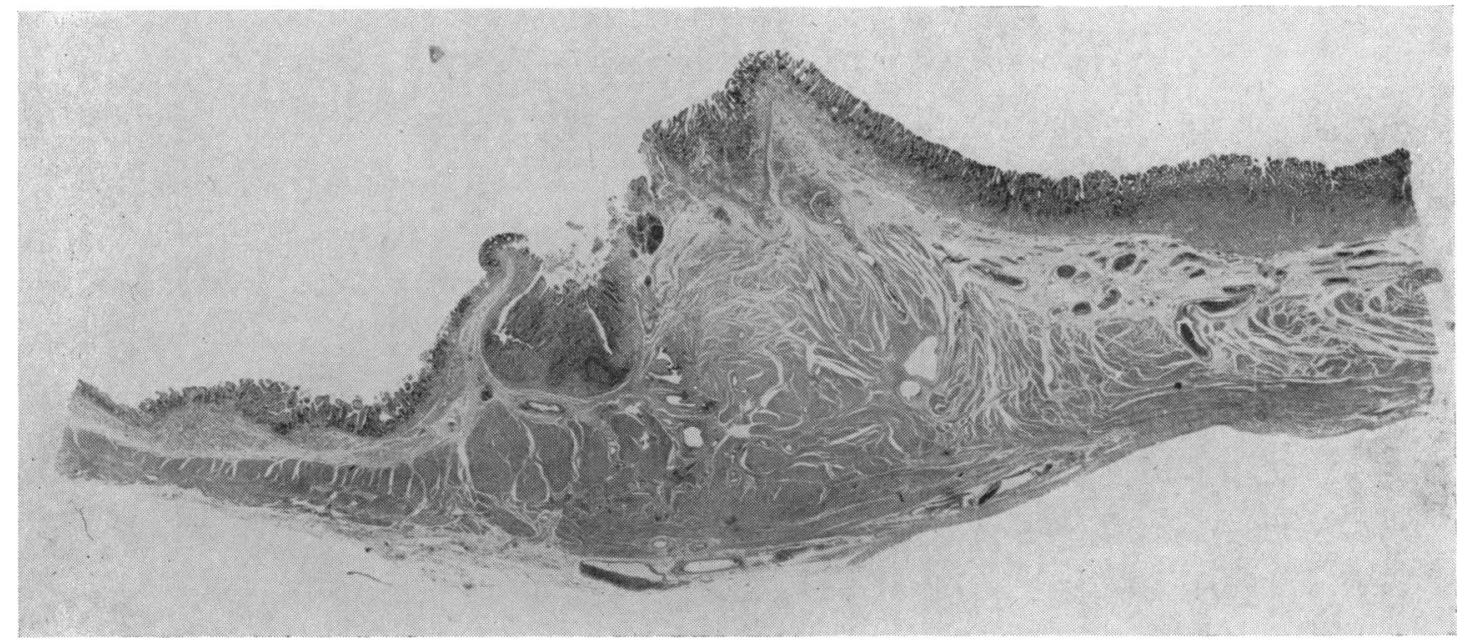

FIG. 3. Transverse section through the whole tumour revealing its submucosal site and penetration into the muscle (Case 3). 


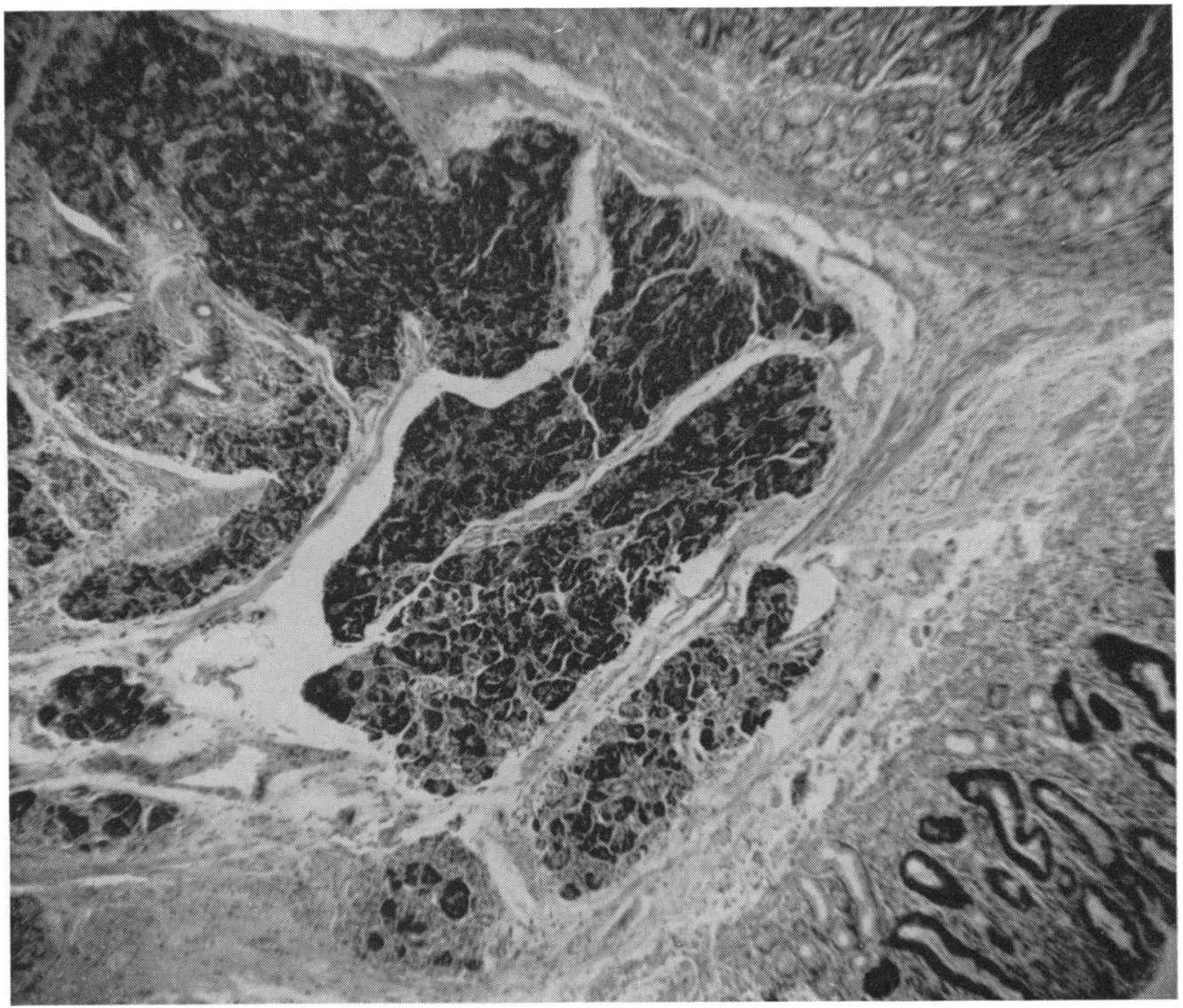

FIG. 4. Microscopic section showing well-differentiated acinar tissue (Case 3).

On examination the patient was of slight build but adequate nutrition. The abdomen was tense but not tender. There was slight discomfort on deep pressure under the left costal margin. The liver and spleen were not palpable. Other systems were within normal limits.

A barium meal showed a gastro-enterostomy with a good functioning anastomosis but no other abnormality. Haemoglobin was $100 \%$, E.S.R. $2 \mathrm{~mm}$./one hour, W.B.C. $4,400 /$ c.mm., with a normal differential count. Tests for occult blood in the stools were negative on three occasions. Gastric washings were cytologically negative for malignant cells. The serum amylase level was less than 130 units. A cholecystogram was normal.

A therapeutic trial of conservative therapy with a rigid diet and antacid and antispasmodic medication failed to ameliorate the symptoms. Barium studies were repeated but again failed to reveal any abnormality.

On account of the persistence of symptoms, laparotomy was performed. At first no cause could be found, but critical palpation of the stomach revealed a small area of induration just proximal to the pylorus. Gastrotomy showed this to be a minute nodule containing a small recess. The mucosa was not ulcerated.
The nodule was excised together with the gastric antrum (Fig. 2), the gastro-enterostomy being converted to a Polya gastrectomy.

Histology showed the nodule to be heterotopic pancreas involving the muscle layers and submucosa (Figs. 3 and 4).

The patient has been symptom-free since the operation.

CASE 4 This was a 45-year-old woman with a 13-year history of cyclical right subcostal pain. The attacks lasted from four to eight weeks with remissions of similar duration and bore no relation to meals and had no aggravating or relieving factors. Four months before admission the pain improved but the patient began to vomit. Vomiting occurred two hours after meals, was associated with nausea, and was copious in quantity but not projectile. Two weeks before admission the vomiting eased considerably and the pain returned in the same right subcostal site, now radiating through to the back. It woke her at night and was more definitely related to meals and also partially relieved by milk and antacid medication.

On examination the patient looked fit, showing no 
dehydration or signs of alkalosis. The abdomen was soft, without visible peristalsis or succussion splash. The liver and spleen were not palpable. Blood pressure was $160 / 95 \mathrm{~mm}$. $\mathrm{Hg}$, but otherwise no abnormal physical signs were demonstrated.

A barium meal radiological examination three years previously had shown 'old scars of a duodenal ulcer'. Barium studies were repeated one month before admission and showed marked delay in gastric emptying. Further studies after admission showed a spastic and slightly tender duodenal cap, but no ulcer crater was demonstrable. There was some resting juice and increased peristalsis, but the stomach was empty at five hours.

An intravenous cholecystogram showed normal filling of the gall bladder which failed to empty in 24 hours and still contained dye in 48 hours. Haemoglobin was $86 \%$, W.B.C. 7,200/c.mm., with a normal differential count. Tests for occult blood in the stools were negative on three occasions.

Subtotal gastrectomy was performed. At operation pyloric stenosis with scarring of the first part of the duodenum was found. There were numerous adhesions involving the common bile duct.

The operation specimen showed an oval excavation $0.7 \times 0.5 \mathrm{~cm}$. on the posterior wall of the duodenum, associated with scarring. Adjacent to this was a firm, oval, bright yellow nodule $0.8 \mathrm{~cm}$. in diameter situated intramurally. Microscopy showed the nodule to be heterotopic pancreatic tissue including acini, ducts, and islet cell tissue involving the muscularis and submucosa. There was an interruption of the muscularis replaced by fibrous tissue partially covered by thin mucosa indicating the site of an old healed ulcer.

\section{COMMENT}

All these patients suffered symptoms of considerable duration and degree. At the time of operation there was no evidence of any alternative causative pathology in the first three, and even in the fourth the original duodenal lesion was soundly healed. There was no histological evidence of active ulceration and a considerable number of blocks were carefully examined in order to be certain of this point (T.E.F.). In conclusion we wish to emphasize that pancreatic heterotopia is by no means exceptionally rare and that in more than half the instances it is sited within $5 \mathrm{~cm}$. of the pylorus. When in this situation it seems virtually certain that it will sooner or later give rise to symptoms of troublesome severity. Pre-operative recognition permits of a very much more conservative surgical procedure, i.e., local resection, the results of which are gratifyingly satisfactory.

\section{REFERENCES}

Ballinger, J. (1941). Hypoglycemia from metastasizing insular carcinoma of aberrant pancreatic tissue in the liver. Arch. Path. (Chicago), 32, 277-285.

Barbosa, J. J. de C., Dockerty, M. B., and Waugh, J. M. (1946). Pancreatic heterotopia, review of literature and report of 41 authenticated surgical cases of which 25 were clinically significant. Surg. Gynec. Obstet., 82, 527-542.

Bradley, R. L., Klein, M. M., and Levy, F. (1956). Gastric heterotopic pancreas with hemorrhage. Gastroenterology, 30, 297-300.

Busard, J. M., and Walters, W. (1950). Heterotopic pancreatic tissue. Arch. Surg. (Chicago), 60, 674-682.

Denson, J. W. (1957). Aberrant pancreatic tissue in gastric wall: report of four cases simulating peptic ulcer. Amer. Surg., 23, 568-576.

Eklöf, O. (1961). Accessory pancreas in the stomach and duodenum. Acta chir. scand., 121, 19-29.

Hudock, J. J., Wanner, H., and Reilly, C. J. (1956). Acute massive gastro-intestinal hemorrhage associated with pancreatic heterotopic tissue of the stomach. Ann. Surg., 143, 121-125.

Krogh, H. K. (1957). Aberrant pancreas. Nord. Med., 58, 1892-1895.

Littner, M., and Kirsh, I. (1952). Aberrant pancreas in the gastric antrum. Radiology, 59, 201-211.

Martinez, N. S., Morlock, C. G., Dockerty, M. B., Waugh, J. M., and Weber, H. M. (1958). Heterotopic pancreatic tissue involving the stomach. Ann. Surg., 147, 1-12.

Nelson, R. S., and Scott, N. M., Jr. (1958). Heterotopic pancreatic tissue in the stomach - gastroscopic features. Gastroenterology, $34,452-459$.

Pearson, S. (1951). Aberrant pancreas. A.M.A. Arch. Surg., 63, 168-184.

Rooney, D. R. (1959). Aberrant pancreatic tissue in the stomach. Radiology, 73, 241-244.

Strelinger, A. (1957). Ectopic pancreatic tissue in stomach wall with unusual symptomatology. Gastroenterology, 33, 493-498.

Vidgoff, I. J. (1957). Massive hemorrhage due to aberrant pancreatic tissue in the cardia of the stomach. Amer. J. Surg., 93, 423-426. 